\title{
Morphological characterization of apple varieties found in yasin valley, gilgit-baltistan, Pakistan
}

\begin{abstract}
Apple (Malus pumila) is a deciduous perennial tree, belongs to the family Rosaceae. Among 95 apples producing countries, Pakistan ranks $22^{\text {nd }}$. During 2016, a total of 89.330 million tons of apple was produced. Pakistan produced hardly half a million ton (0.590). Since 2000, increased yield has helped production enhancement in the country. Apple from Gilgit-Baltistan is known for its taste. Several indigenous varieties exist in the area but due to negligence land races are near extinction. After apricot, it is the second highest cultivated species. Thousands of poor families rely heavily on income from sale of apple. Basic research has never been adopted to test morphological similarities and dissimilarity between exotic and indigenous races. This study has attempted to characterize cultivated apple varieties grown in Yasin Valley. Assessment against leaves, stem, and seed and fruit morphology of seven varieties revealed that on an average fresh apple fruit carries $110.14 \mathrm{~g}$ weight following a mean height of $5.76 \mathrm{~cm}$ and $6.2 \mathrm{~cm}$ diameter. Faransisi, name after imported variety from France by AKRSP show highest mean weight value $(159.392 \mathrm{~g})$ followed by Khama (130.8g), Iskarkh (126.846g), Shoot (122.416g), Basuti (93.898g), Dhan (78.198g) and Haray $(59.5 \mathrm{~g})$. All varieties carry a mean number of 5.06 (min. 5, max. 5.4, Std. Error. 0.05, Std.Dev. 0.15) seed chambers in each fruit, each fruit contains an average of 9.45 (min. 8.4, max. 10.6, Std. Error. 0.29, Std.Dev. 0.78) seeds and a mean weight value of total number of seeds in each fruit is $8.09 \mathrm{~g}$ ( min. $7.95 \mathrm{~g}$, max. $8.25 \mathrm{~g}$, Std. Error. 0.04, Std.Dev. 0.11)
\end{abstract}

Keywords: apple fruit, tree, land races, apricot, crops, falaa, temperate regions, anticancer
Volume 2 Issue I - 2018

Parveen N, Khan T

Department of Biological Sciences, Karakoram International University, Pakistan

\author{
Correspondence: Tika Khan, Department of Biological \\ Sciences, Karakoram International University, Gilgit, Gilgit- \\ Baltistan, Pakistan, Tel 009234684803 60, \\ Email tika.khan@kiu.edu.pk
}

Received: January 08, 2018 | Published: February 19, 2018

\section{Introduction}

The proverb "An apple a day keeps the doctor away" addressing the health effects of the fruit. Apple is the most important temperate fruit crop and has been cultivated in Asia and Europe from antiquity. Apple is a fruit of temperate climate and it is native to many parts of Europe and Asia. ${ }^{1}$ Worldwide, apple is the four most broad produced short-lived fruits, and in more than 94 countries, its production is 69.60 million metric tons fresh weight, yield from 4.85 million hectares of land. M. pumila is commonly known as apple in English, and pommier common in French ${ }^{2}$ (Figure 1).

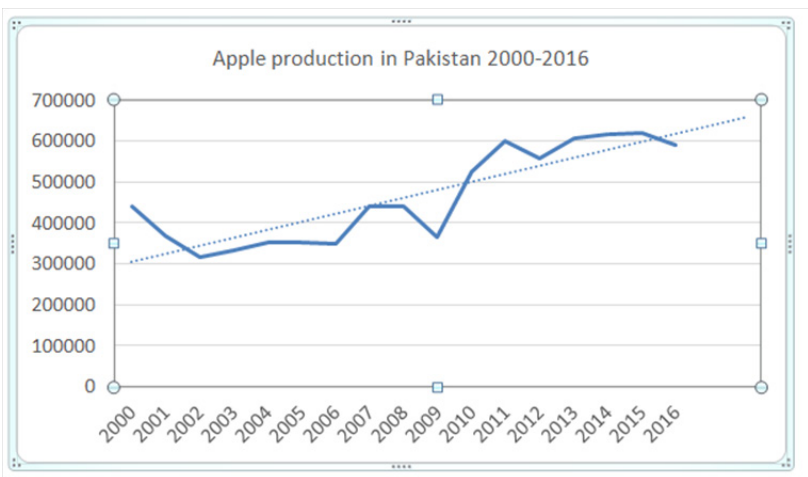

Figure I Apple production in Pakistan 2000-2016.

Locally in Brushaski language it is called Bhalt and in Shina it is known as 'Falaa'. The genus Malus belongs to the Rose family (Rosaceae), which consists of over 100 genera and 300 species. Its members are distributed worldwide, most commonly these are distributed in temperate regions. ${ }^{3}$ Throughout the history of cultivation of M. pumila, more than ten thousand cultivars have been developed but now many of them are lost. ${ }^{3,4}$ And now currently 100 cultivars are grown marketable. ${ }^{5} \mathrm{M}$. pumila is of different sized, small to medium, much-branched, these are deciduous trees having a single trunk and a broadly spreading canopy. The cultivated trees are generally $2-5 \mathrm{~m}$ tall while the wild trees can reach $10-15 \mathrm{~m}$ in height.

It is cultivated worldwide as a fruit tree and is the most widely grown species. It is prone to a number of fungal, bacterial and pest problems. These can be controlled by many organic and non-organic means. Apples carry important ingredients and used in many deserts, such as apple pie, apple crumble and apple cake. Apples have several useful aspects for everybody's health regarding their high capacity in phenolic contents. Phenolic compounds include a significant class of phytochemicals that possess various biological functions such as astringent, antioxidant, anticancer, anti-inflammation, and antibacterial activity. Malus domistica help to fight against inflammation, Diabetes melitus, heart diseases,asthma and constipation ${ }^{6}$ (Figure 2).

Deep, well trained, loaming soils with PH 6-7 are best but apples are grown on aqueous wide variety of soils worldwide. The apple is deciduous tree, generally standing 6 to 15 feet tall in cultivation. The fruit mature in late summer or autumn.

The tree originated in Central Asia, where its wild ancestor, Malus siversii, is still found today. ${ }^{7}$ Apples have been grown for thousands of years in Asia and Europe, and were brought to North America by European colonists. Apples have religious and mythological significance in many cultures, including Norse, Greek and European Christian tradition.+ 


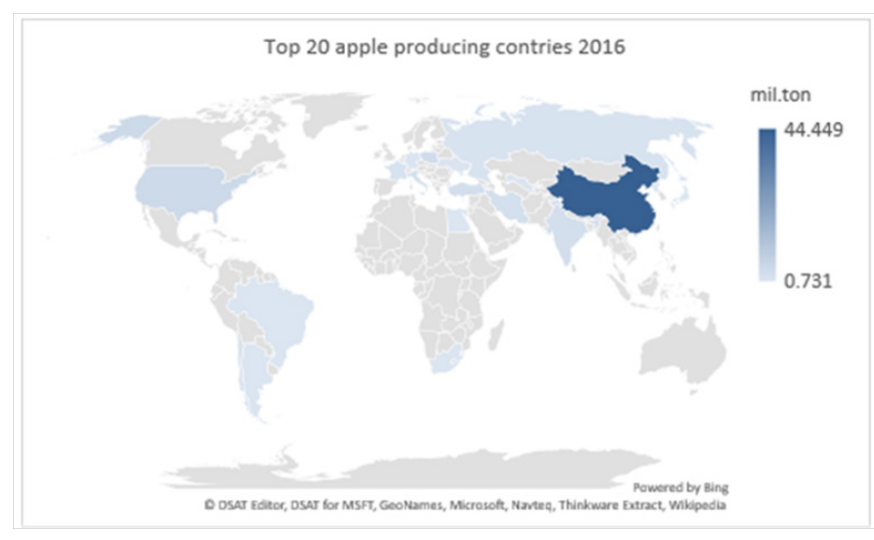

Figure 2 Top 20 Apple producing Countries 2016.

Different cultivars are bred for various tastes and uses, including cooking, eating raw and cider production. In Pakistan the apple is the main source of earning of many peoples. Gilgit, the area which is one of the main producers of apple in Pakistan. It produces many varieties of apple, like Shoot, Dhan, Basuti, Harai, Khama, Faransaisi, Iskarkh. It is the main source of income, many people depends on apple for their income. Apple from Gilgit-Baltistan is known for its taste. Several indigenous varieties exist in the area but due to negligence land races are near extinction. After apricot, it is the second highest cultivated species. Thousands of poor families rely heavily on income from sale of apple. Basic research has never been adopted to test morphological similarities and dissimilarity between exotic and indigenous races. This study has attempted to characterize cultivated apple varieties grown in Yasin Valley.

\section{Materials and methods}

Study was carried out during 2016 in Yaseen Valley of district Ghizer (map and location in the figure 3). It is highly mountainous area and bordered with Afghanistan. Most of the year remains cool with chilling winter. People heavily rely on apple production. Valley is famous for healthy apple production. A total of seven verities were taken into considerations which are commonly grown in the area. These varieties are Iskarkh Balt, Faransaisi Bhalt, Khama Bhalt, Haray Bhalt, Shoot Bhalt, Dhan Bhalt and Basuti Bhalt. Data against leaves, fruit, seed and stem was taken from four different villages. Ten plants of each varieity were identified from each village and 10 leaves and fruits were collected for their measurement. Means were calculate $\mathrm{d}$ for leaf length $(\mathrm{cm})$, leaf width $(\mathrm{cm})$, leaf area $\left(\mathrm{cm}^{2}\right)$, fresh fruit weight $(\mathrm{g})$, number of seed chambers in each fruit, number of seeds in each fruit and total weight of total seeds in each fresh fruit $(\mathrm{g})$.

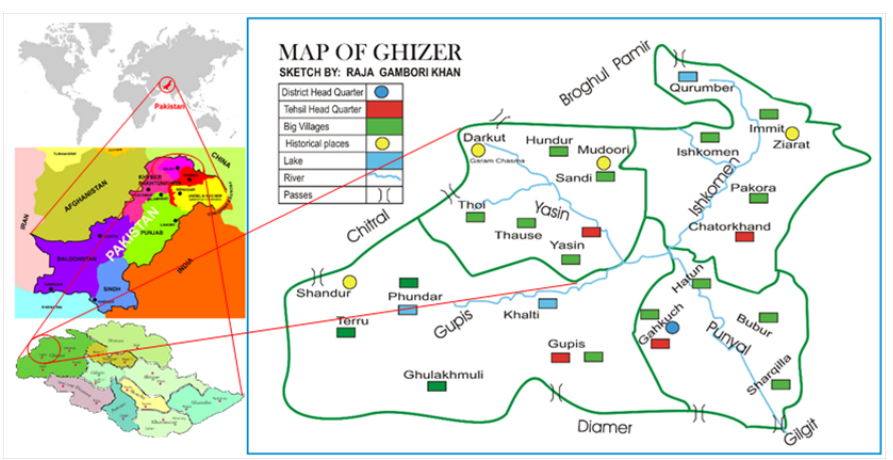

Figure 3 Map of Ghizer.

\section{Results}

Assessment against leaves, stem, seed and fruit morphology of seven varieties revealed that on an average fresh apple fruit carries $110.14 \mathrm{~g}$ weight following a mean height of $5.76 \mathrm{~cm}$ and $6.2 \mathrm{~cm}$ diameter. Faransisi, name after imported variety from France by AKRSP show highest mean weight value (159.392 g) followed by Khama (130.8g), Iskarkh (126.846g), Shoot (122.416g), Basuti $(93.898 \mathrm{~g})$, Dhan $(78.198 \mathrm{~g})$ and Haray $(59.5 \mathrm{~g})$. All varieties carry a mean number of 5.06 (min. 5, max. 5.4, Std. Error. 0.05, Std. Dev. 0.15 ) seed chambers in each fruit, each fruit contains an average of 9.45 (min. 8.4, max. 10.6, Std. Error. 0.29, Std. Dev. 0.78) seeds and a mean weight value of total number of seeds in each fruit is $8.09 \mathrm{~g}$ ( $\mathrm{min}$. 7.95g, max. 8.25g, Std. Error. 0.04, Std. Dev. 0.11).

Based on the data Hierarchical Clustering Analysis (Figure 4) dendrogram revealed that all these varieties can be grouped into two major varieties i.e. Group A and B. Group A include varieties Iskarkh, Shoot, Faransisi, Khama and Basuti. Similarly, group B include Haray and Dhan showed closely relatedness. In group A, there are a three inferior taxon may be called as forma, these are A1 with Iskarakh and Shoot, A2 contains Faransisi and Khama whereas A3 having single varieity i.e. Basuti.

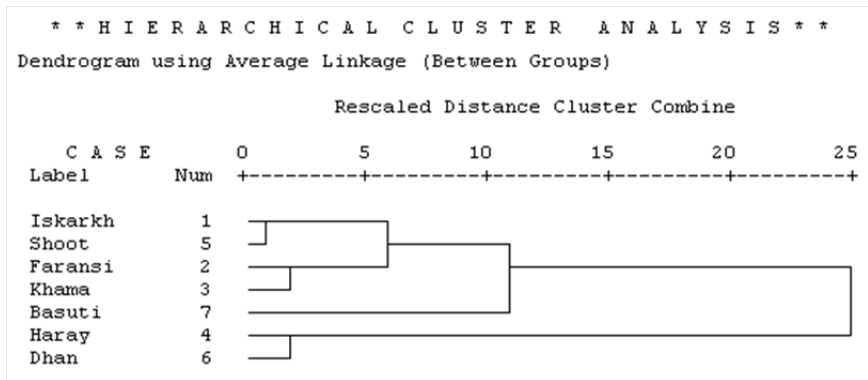

Figure 4 Hierarchical Clustering Analysis.

\section{Discussion}

Due to increasing reliance on market for their economic survival, poor farmers are replacing land races with the exotic verities rapidly. This will lead to loss of important climatically and pathogenically resistant genes from the gene pool. Therefore, it is important to preserve and promote unique germ plasma and further investigations are critical to sustain them for future generations.

\section{Acknowledgements}

None.

\section{Conflict of interest}

Authors declare that there is no conflict of inertest.

\section{References}

1. Sandor F. Apple Production. Perennial Crop Support Series Jalalabad, Afghanistan. Manual produced by Roots of Peace, USAID, USA; 2008. p. $1-44$.

2. USDA-ARS. Germplasm Resources Information Network-(GRIN). 2012.

3. Velasco R, Zharkikh A, Affourtit J, et al. The genome of the pumilated apple (Malus x pumila Borkh.). Nature Genetics. 2010;42(10):833-839. 
4. Qian GZ, Liu LF, Tang GG. Proposal to conserve the name Malus pumila against M. pumila, M. communis, M. frutescens, and Pyrus dioica (Rosaceae). Taxon. 2010;59(2):650-652.

5. Hampson CR, Kemp H. Characteristics apple cultivars. In: Ferree DC, Warrington IJ, editors. Apples: Botany, production and uses. Wallingford, UK: CABI publishing, CAB international; 2003. p. 61-90.

6. Mazed MA, Mazed S. U.S. Patent No. 20100021533A1. Washington, DC: U.S. Patent and Trademark Office. 2009. p. 1-31.
7. Sagar S. Role of natural toothbrushes in containing oral microbial flora-A review. Asian Journal of Pharmaceutical and Clinical Research. 2015;8(4):29-33.

8. Campbell HA, Pastina ACL. How the iPhone became divine: new media, religion and the intertextual circulation of meaning. New Media \& Society. 2010;12(7):1191-1207. 